\title{
First record of the cyanobacterial genus Wilmottia (Coleofascicula- ceae, Oscillatoriales) from the South Orkney Islands (Antarctica)
}

\author{
Ranina Radzi ${ }^{1}$, Faradina Merican ${ }^{1,2, *}$, Paul Broady ${ }^{3}$, Peter Convey ${ }^{4,5}$, Narongrit \\ Muangmai ${ }^{6,7}$ Wan Maznah Wan Omar ${ }^{1,2}$ and Sébastien Lavoué ${ }^{1}$ \\ ${ }^{1}$ School of Biological Sciences, Universiti Sains Malaysia, Minden, 11800 Penang, Malaysia \\ ${ }^{2}$ National Antarctic Research Centre, University of Malaya, 50603 Kuala Lumpur, Malaysia \\ ${ }^{3}$ School of Biological Sciences, University of Canterbury, Christchurch 8041, New Zealand \\ ${ }^{4}$ British Antarctic Survey, NERC, Cambridge CB3 OET, UK \\ ${ }^{5}$ Department of Zoology, University of Johannesburg, Auckland Park 2006, South Africa \\ ${ }^{6}$ Faculty of Fisheries, Kasetsart University, Bangkok 10900, Thailand \\ ${ }^{7}$ Graduate School of Integrated Science for Life, Hiroshima University, Hiroshima 739-0046, Japan
}

Two cyanobacterial morphotypes isolated from Signy Island, South Orkney Islands, maritime Antarctica were characterised using a polyphasic approach combining morphological, cytological and molecular analyses. These analyses showed that the strains grouped with members of the genus Wilmottia. This genus currently includes three species, $W$. murrayi, W. stricta, and W. koreana. Both morphotypes analysed in this study were placed within the clade of W. murrayi. This clade showed a well-supported separation from Antarctic and New Zealand strains, as well as strains from other regions. W. murrayi was first described from Antarctica and is now known from several Antarctic regions. Confirmation of the occurrence of $W$. murrayi at Signy Island significantly extends its known distribution in Antarctica. In addition, a new combination, $W$. arthurensis, is suggested for Phormidium arthurensis.

Key Words: Antarctic cyanobacteria; distribution; polyphasic analysis; taxonomy; 16S rDNA

\section{INTRODUCTION}

The genus Wilmottia O. Strunecky, J. Elster \& J. Komárek was established from material originally referred to Phormidium Kützing ex Gomont that originated from Antarctica. According to Strunecký et al. (2011), the genus Wilmottia originally comprised a single species, $W$. murrayi (West \& G. S. West) Strunecký, Elster \& Komárek, which was described based on a polyphasic evaluation of Phormidium-like strains isolated from Antarctic localities. Subsequently, W. murrayi has been recorded from diverse habitats around the Antarctic, ranging from freshwater lakes (Boyer et al. 2002, Šabacká and Elster 2004, Casamatta et al. 2005, Taton et al. 2006, Comte et al. 2007) to various soil conditions (Šabacká and Elster 2004, Komárek and Anagnostidis 2005, Comte et al. 2007), stagnant to slightly saline water (Komárek and Anagnostidis 2005), seepages (Šabacká and Elster 2004, Comte et al. 2007), and even on whale bones (Strunecký et al. 2010). The species has also been recorded from New Zealand rivers (Wood et al. 2009, Heath et al. 2010) and on wet rocks on the seashore in Brazil (Lokmer 2007). A second

\section{(ब) (1) $(2)$}

This is an Open Access article distributed under the terms of the Creative Commons Attribution Non-Commercial License (http://creativecommons.org/licenses/by-nc/3.0/) which permits unrestricted non-commercial use, distribution, and reproduction in any medium, provided the original work is properly cited.
Received November 30, 2020, Accepted May 6, 2021

* Corresponding Author

E-mail: faradina@usm.my

Tel: +604-653-5878, Fax: +604-656-5125 
species, W. stricta Machado-de-Lima, Martins et Branco has been described from streams of São Paulo, Brazil (Machado-de-Lima et al. 2017).

The genus Wilmottia was initially included within the family Phormidiaceae, but it was later transferred to Coleofasciculaceae based on molecular and ultrastructural evidence (Komárek et al. 2014). Species are described as having solitary trichomes or with several to many trichomes forming fascicles, presenting cylindrical trichome with cells almost isodiametric or longer than wide that are not or only slightly constricted at cross-walls (Komárek and Anagnostidis 2005). Solitary granules are present in vegetative cells and are occasionally placed near the cross-walls (Komárek and Anagnostidis 2005). The apical cell is rounded or slightly conical without any distinctive feature, which conforms to Phormidium group IV (Komárek and Anagnostidis 2005). The genus as currently described possesses characteristics that are morphologically identical to those of Phormidium, thus hindering reliable morphological assessment. Hence, representatives of this genera can only be distinguished with confidence based on molecular evaluation.

In a broad-scale floristic survey conducted on Signy Island (South Orkney Islands, $60.7170^{\circ} \mathrm{S}, 45.6000^{\circ} \mathrm{W}$ ), Broady (1979) recorded the occurrence of five Phormidium morphospecies: P. autumnale Gomont, P. foveolarum Gomont, $P$. frigidum F. E. Fritsch, P. priestleyi F. E. Fritsch, and $P$. cf. rubroterricola N. L. Gardner. These identifications were based solely on morphological features and Signy Island isolates have not been subjected to any subsequent molecular assessment. However, recent molecular evaluation of $P$. priestleyi resulted in the proposition of the new genus Phormidesmis Turicchia, Ventura, Komárková \& Komárek with Phormidesmis priestleyi (F. E. Fritsch) Komárek, Kastovský, Ventura, Turicchia \& Smarda as the type species (Komárek et al. 2009). This study illustrated the potential of genetic data to complement the morphological approach in determining which species belong to the genus Phormidium. In the current study, we report the polyphasic characterization of two cyanobacterial morphotypes that resemble $P$. cf. rubroterricola as described by Broady (1979).

\section{MATERIALS AND METHODS}

\section{Sample origin and culture conditions}

Two samples were obtained from Signy Island during the austral summer of 2015/16: (1) sample A $\left(60^{\circ} 42.570^{\prime}\right.$

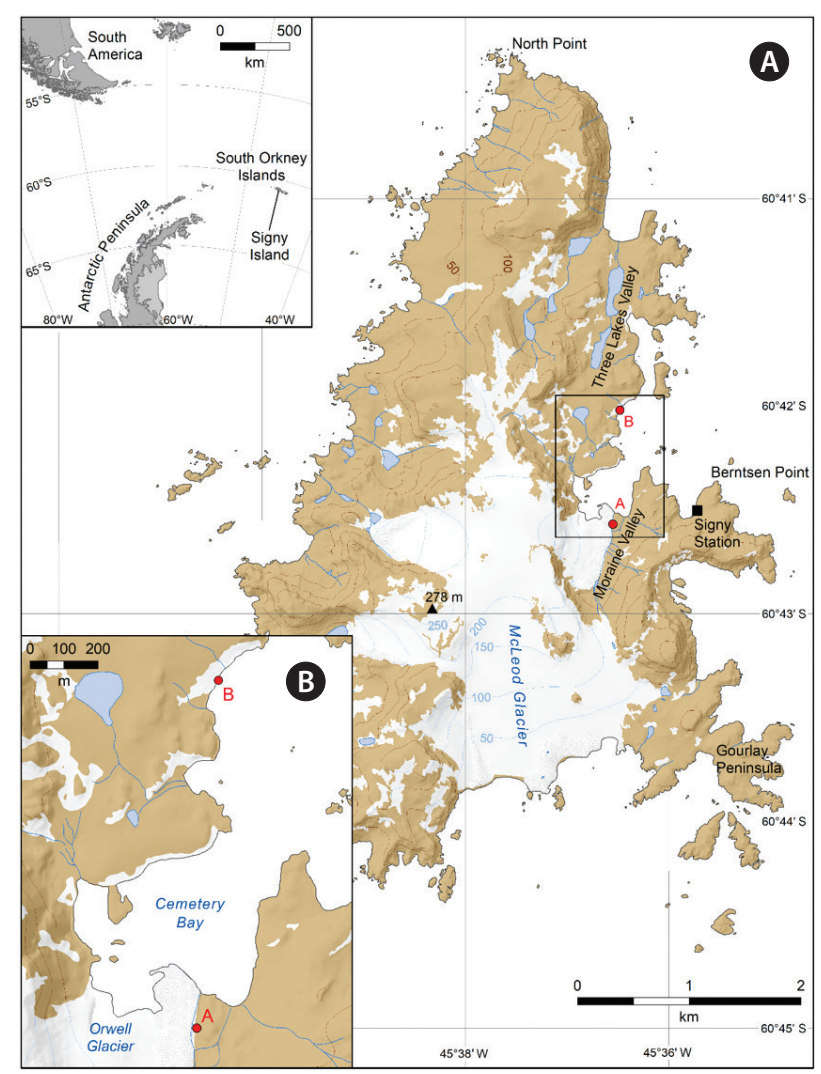

Fig. 1. Map showing the sampling locations on Signy Island, South Orkney Islands, Antarctica. (A) Location of Signy Island, South Orkney Islands, in relation to the Antarctic Peninsula and southern South America. (B) Enlargement which identifies sampling locations that are also shown within the box on the main figure. Samples A and B were obtained at the northern end of the lateral moraine of Orwell Glacier in Cemetery Bay and on the slope north-west of Waterpipe Beach, respectively. Map prepared by Laura Gerrish (BAS Mapping and Geographic Information Centre).

S, $45^{\circ} 36.550^{\prime} \mathrm{W}$ ) at the northern end of the lateral moraine of Orwell Glacier in Cemetery Bay; and (2) sample B $\left(60^{\circ} 42.020^{\prime} \mathrm{S}, 45^{\circ} 36.480^{\prime} \mathrm{W}\right)$ on the slope north-west of Waterpipe Beach (Fig. 1). Both samples were collected from rock surfaces using sterile equipment. Sample A comprised of moss while sample B comprised of lichens and moss. They were frozen soon after collection at the research station of the British Antarctic Survey on Signy Island and transported frozen $\left(-20^{\circ} \mathrm{C}\right)$ in sterile containers to Universiti Sains Malaysia, Penang, Malaysia. A small amount of each sample was streak inoculated onto $1 \%$ agarised full-strength BG-11 medium in Petri dishes (Rippka et al. 1979), supplemented with $1 \%$ cycloheximide to prevent undesirable growth of eukaryotes (Bolch and Blackburn 1996). Cultures were incubated for three weeks under $24 \mathrm{~h}$ light provided by a cool white fluorescent lamp at $27 \mu \mathrm{mol} \mathrm{m}^{-2} \mathrm{~s}^{-1}$ at $15 \pm 2^{\circ} \mathrm{C}$. Unialgal cultures 
of filamentous cyanobacteria were established by inoculation onto fresh medium of small amounts of filaments removed from the edges of developing colonies.

\section{Morphological characterization}

Morphological examination was carried out on the strains in cultures using an Olympus BX-53 bright field microscope (Olympus America Inc., Center Valley, PA, USA) at 100-2,000× magnification. Photomicrographs were taken. Illustrations were made with the aid of a camera lucida The following morphological features were recorded for both morphotypes: filament and trichome width, cell shape, apical cell shape, sheath morphology, cell colour, and presence of granules. Measurements were taken from 30 replicates of randomly chosen filaments for each specimen. The characteristics of the studied morphotypes were compared with data presented in Broady (1979), Komárek and Anagnostidis (2005), Strunecký et al. (2011), and Machado-de-Lima et al. (2017).

\section{Transmission electron microscopy}

Filaments taken from week three cultures of both morphotypes were fixed for $24 \mathrm{~h}$ in McDowell-Trump fixative solution (McDowell and Trump 1976) prepared in $0.1 \mathrm{M}$ phosphate buffer, and then post-fixed with $1 \%$ osmium tetroxide. Upon fixation, the samples were dehydrated in an ethanol series (50, 75, 95, and $100 \%$ ), 50 and $75 \%$ ethanol for $15 \mathrm{~min}$ each, followed by 2 times dehydration in the following: $95 \%$ ethanol for $15 \mathrm{~min}, 100 \%$ ethanol for $30 \mathrm{~min}$ and $100 \%$ acetone for $10 \mathrm{~min}$. The samples were then embedded in Spurr's Low Viscosity epoxy resin (Spurr 1969) mixed in a rotator overnight. Ultrathin sections of specimens $(<0.1 \mu \mathrm{m})$ were prepared using a PowerTome XL ultramicrotome (Labtech, Quebec, Canada) with a glass knife. To improve contrast, these sections were treated with uranyl acetate and lead citrate (Reynolds 1963). Thin sections were collected on copper grids. A JEM 2000FX transmission electron microscope (JEOL, Tokyo, Japan) was used to observe the samples operating at $100 \mathrm{kV}$.

\section{Molecular analyses}

DNA was extracted using the G-spin for bacterial genomic DNA extraction kit (iNtRON Biotechnology, Seongnam, Korea) according to the manufacturer's protocol. The quality of extracted DNA was determined using a NanoDrop Quawell UV Spectrophotometer Q3000
(Thermo Fisher Scientific, Waltham, MA, USA) for \pm 1.5 $\mu \mathrm{g} \mathrm{mL} \mathrm{m}^{-1}$ between 12 and $24 \mathrm{~h}$. The 16S rDNA gene sequences were amplified using the combination of primers 2 (5'-GGG GGA TTT TCC GCA ATG GG-3') and 3 (5'CGC TCT ACC AAC TGA GCT A-3') (Boyer et al. 2001). The reaction mix comprised $25 \mu \mathrm{L}$ of MyTaq ${ }^{\mathrm{TM}}$ Red Mix (Meridian Bioscience, Cincinnati, OH, USA), $1 \mu \mathrm{L}$ of each forward and reverse primer, $2 \mu \mathrm{L}$ of DNA template, and $21 \mu \mathrm{L}$ of ultra-pure water, giving a final volume of $50 \mu \mathrm{L}$. Polymerase chain reaction (PCR) was carried out using a Thermal Cycler (Bio-Rad, Hercules, CA, USA). Thermal cycling conditions were set as follows: $95^{\circ} \mathrm{C}$ for $2 \mathrm{~min}$, $95^{\circ} \mathrm{C}$ for $15 \mathrm{~s}, 55^{\circ} \mathrm{C}$ for $15 \mathrm{~s}$ ( 30 cycles), $72^{\circ} \mathrm{C}$ for $20 \mathrm{~s}$ followed by $7 \mathrm{~min}$ extension at $72^{\circ} \mathrm{C}$. Once the reaction was completed, the integrity of the PCR product was verified using $2 \%$ agarose gel. PCR products were sequenced at NHK Bioscience Solutions Sdn. Bhd. (Korea) using the Sanger sequencing method and the same primer pair used for PCR reactions.

\section{Phylogenetic analyses}

The chromatograms were checked, edited, and trimmed manually to achieve maximum homology. The $16 \mathrm{~S}$ rDNA consensus sequences were built by assembling the forward and reverse sequences. Sequence alignments between newly determined sequences and a selection of GenBank sequences were made using the MUSCLE algorithm in the Geneious 11.0 software package (http:// www.geneious.com) (Kearse et al. 2012). The data set included 60 operational taxonomic units, consisting of two sequences newly obtained in this study together with additional sequences retrieved from GenBank of closely related species of Wilmottia, more distantly related species of Phormidium sensu stricto and one outgroup taxon (Gloeobacter violaceus FR798924). New sequences generated in this study have been deposited in GenBank under accession numbers USMFMS1 MN656000 and USMFMS2 MN656001.

Phylogenetic analyses were performed using two different methods: maximum likelihood (ML) and Bayesian inference (BI). The program Kakusan4 determined the best-fit model of DNA substitution (Kanehisa et al. 2011). ML analyses were performed with W-1Q-TREE (http:// iqtree.cibiv.univie.ac.at) (Trifinopoulos et al. 2016). The analysis used the general time-reversible invariant-sites nucleotide substitution model with the default parameters. Bootstrap proportions were calculated (1,000 replicates) to assess the robustness of each node. BI analyses were performed using MrBayes v3.1.2 (Ronquist and 

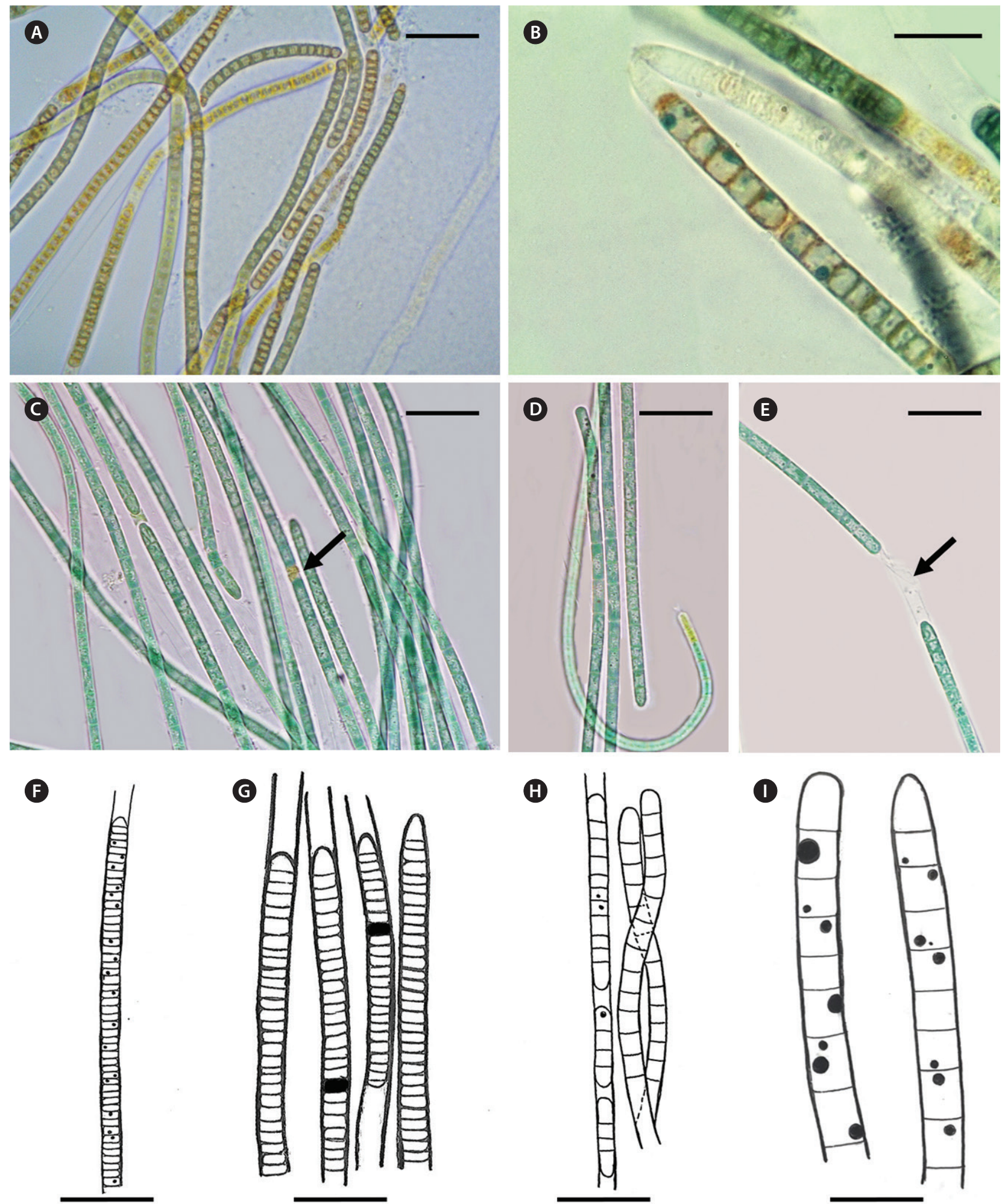

Fig. 2. Detailed morphology of cultured strains. Wilmottia murrayi USMFMS1 (A, B, F \& G). Light microscopy: trichomes olive green to brownish with distinctly constricted cell walls (A) and cells with granules, sheath firm and colourless (B). Illustrations: cells with granules, sheath firm and colourless (F) and apical cells round to cylindrical, necridic cells with dense contents (G). Wilmottia murrayi USMFMS2 (C-E, H \& I). Light microscopy: filaments bright blue-green to pale blue, necridic cell (arrow) (C), apical cells rounded to cylindrically round (D), and sheath, thin and colourless (arrow) (E). Illustration: longer than wide cells, granulated at cross-walls $(\mathrm{H})$ and trichomes not constricted at cross walls, rounded apical cells (I). Scale bars represent: A, C-F \& H, $10 \mu \mathrm{m} ; \mathrm{B}, \mathrm{G} \& \mathrm{I}, 5 \mu \mathrm{m}$. 
Huelsenbeck 2003). Two independent analyses, each consisting of four Markov chains, were run simultaneously for 1,000,000 generations, sampling every 100 generations. Bayesian posterior probability values was calculated using the remaining trees after a burn in of $25 \%$ of saved trees was removed. ML and BI trees were edited with the program FigTree v1.3.1 (Rambaut 2009). We rooted both phylogenetic trees with the same outgroup (Gloeobacter violaceus FR798924). The uncorrected pairwise genetic distances ( $p$-distance) in MEGA X (Stecher et al. 2020) was also calculated.

\section{RESULTS}

\section{Light microscopy}

Wilmottia murrayi USMFMS1. Fig. 2A, B, F \& G was isolated from sample associated with moss. Macroscopically forming pale blue-green, thin, flat mats spreading over agar surface. Filaments olive-green to slightly brownish, often somewhat curved, rarely straight, long. Sheath thin, firm, colourless (Fig. 2F \& G). Trichomes immotile, distinctly constricted at cross-walls (Fig. 2A). Cells distinctly shorter than wide, (1.9) 2.5-4.4 $\mu \mathrm{m}$ wide, 1.2-3.1 (3.3) $\mu \mathrm{m}$ long, containing small, scattered granules sometimes gathered at cross-walls (Fig. 2B). Apical cell rounded, not attenuated and without calyptra (Fig. $2 \mathrm{G})$. Reproduction by fragmentation of trichomes at necridic cells (Fig. 2G).

Wilmottia murrayi USMFMS2.Fig. 2C-E, H \& I was isolated from sample associated with lichen and moss. Macroscopically forming bright blue-green, thin, flat mats spreading over agar surface. Filaments bright blue green, variously bent, densely entangled or nearly straight and in parallel arrangement, long (Fig. 2C). Sheath thin, firm, and colourless (Fig. 2E). Trichomes motile with slow jerky gliding, not constricted at the cross walls (Fig. $2 \mathrm{H}$ ). Cells mostly almost isodiametric or longer than wide, (2.5) 3.04.0 (4.5) $\mu \mathrm{m}$ wide, 3.0-5.0 (5.6) $\mu \mathrm{m}$ long, often containing one or two large granules at various positions within the cells (Fig. 2I). Apical cell cylindrical to somewhat conical, rounded, not attenuated, without calyptra (Fig. 2D \& I). Reproduction by fragmentation of trichomes at necridic cells (Fig. 2C).

Differences were evident in morphological characteristics between the two strains grown under the same culture conditions and also with previous descriptions of the species (Table 1). Apical cell shape, trichome pigmentation and sheath development were consistent among our strains. Other characteristics were inconsistent, such as the cell width and length, which were smallest in $W$. murrayi USMFMS1. This strain also had trichomes with distinct constrictions at the cross-walls, all other strains were either not constricted or slightly constricted (Table 1). Fascicle formation was absent in the current strains but occurred in two of the four previously studied strains. Necridic cells were present in the current two strains and have not been recorded previously.

\section{Transmission electron microscopy}

Both morphotypes were examined with transmission electron microscopy (Fig. 3A-D) to visualise cytomorphological arrangement and granular inclusions. Thylakoids (3-8 per cell) showed parietal and irregular arrangement when viewed in transverse and longitudinal sections of both morphotypes (Fig. 3A \& B), but were not clearly seen in longitudinal section of USMFMS2 (Fig. 3D). Occasional polyphosphate granules were visible in both morphotypes (Fig. 3A \& C). Carboxysomes were seen only in Morphotype 2 (Fig. 3C \& D). Cell walls were simple (Fig. 3B) and trichomes were enclosed within distinct sheaths (Fig. 3B \& D) for both morphotypes.

\section{Phylogenetic analysis}

The 16S rDNA sequence dataset consisted of 1,472 base pairs (bp), including gaps. Both $\mathrm{ML}$ and BI analyses yielded a congruent topology and therefore only the ML tree is presented (Fig. 4), and $p$-distance is given in Supplementary Table S1. ML tree clearly indicates the monophyletic clade of the genus Wilmottia, including our two samples $(86 \%$ ML bootstrap percentage and $0.98 \%$ BI posterior probability). The genetic divergences ( $p$-distance) within the Wilmottia clade range from 0-3.9\% (Supplementary Table S1). W. murrayi USMFMS1 and $W$. murrayi USMFMS2 are placed within a clade that contains all sequences of $W$. murrayi (98\% ML bootstrap percentage and $100 \%$ BI posterior probability) with small genetic differences ( $p$-distances $0-1.4 \%$ ) (Supplementary Table S1). The largest clade within this includes all sequences of $W$. murrayi as well as three strains labelled Wilmottia sp. and two labelled Phormidium sp. The $W$. murrayi clade is sister to the clade containing $W$. stricta (KY288996), Wilmottia sp. (KU219760), and Phormidium arthurensis (HQ012544), and the genetic divergences between these two clades range from 1.8-3\% (Supplementary Table S1).

Sequences of $W$. murrayi that were retrieved from 


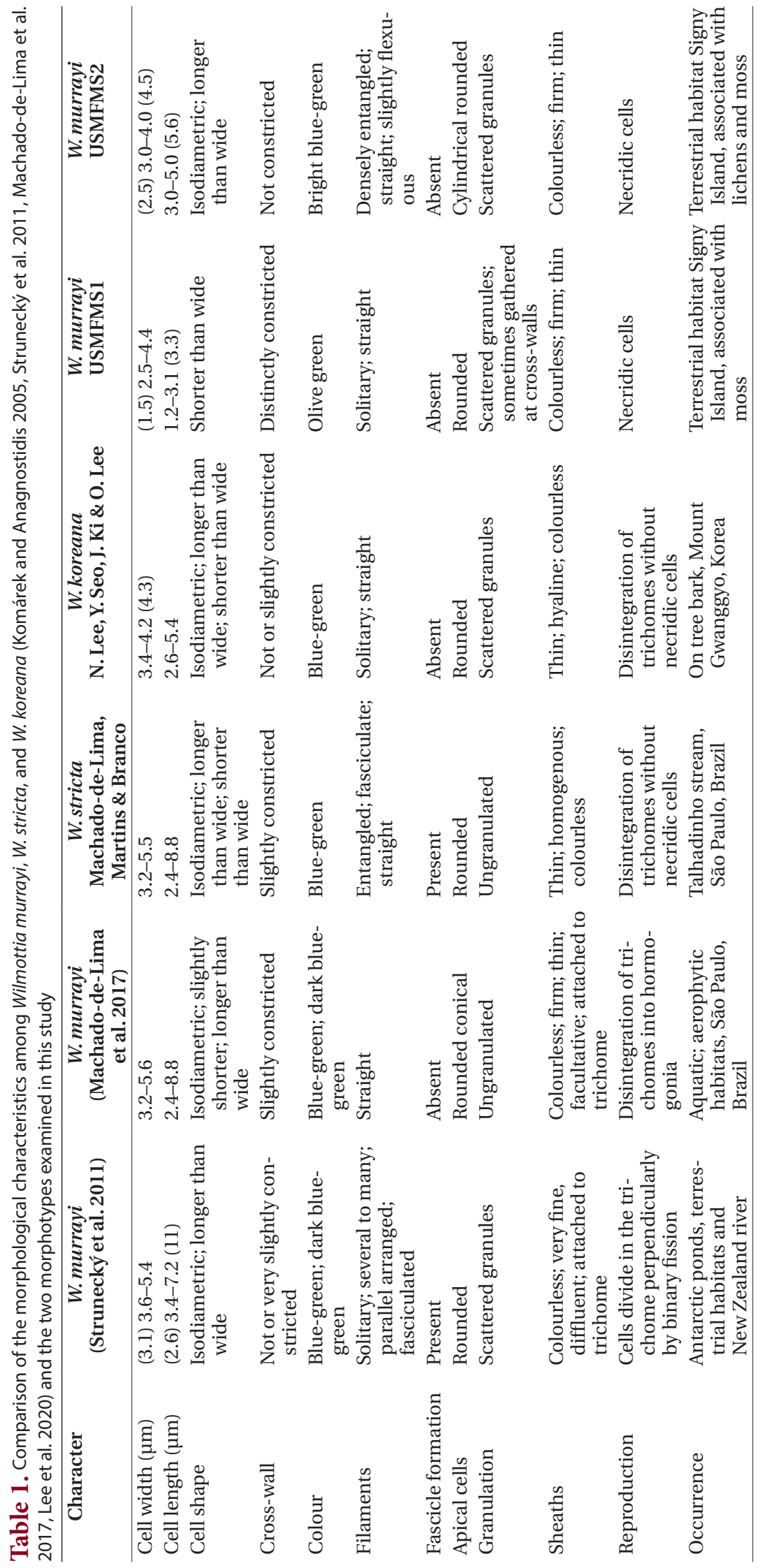



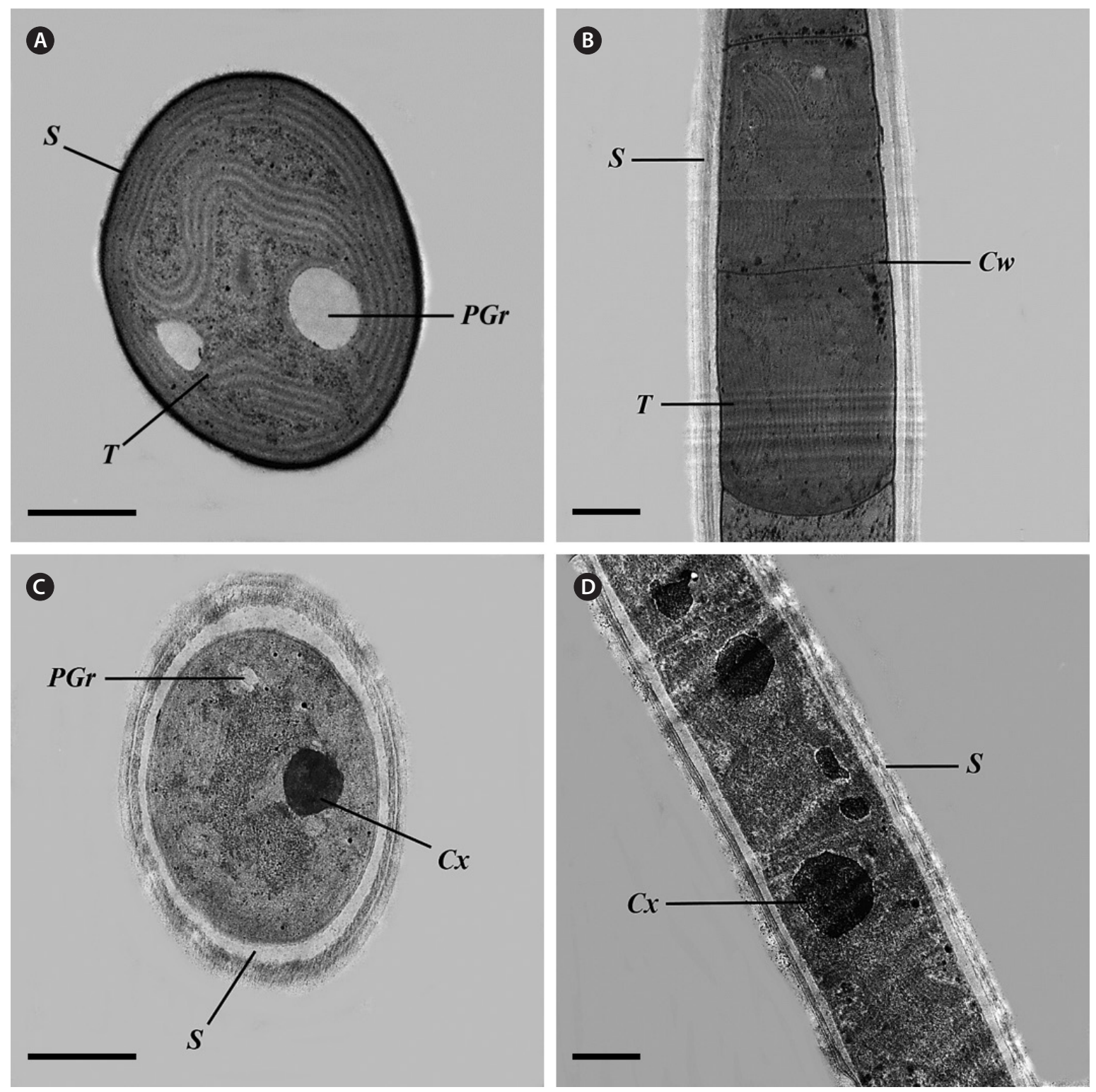

Fig. 3. Transmission electron micrographs. Wilmottia murrayi USMFMS1 (A \& B). Cross-section (A) and longitudinal section (B). W. murrayi USMFMS2 (C \& D). Cross-section (C) and longitudinal section (D). S, sheath; T, thylakoids; PGr, polyphosphate granules; CW, cross-wall; CX, carboxysome. Scale bars represent: A \& C, $500 \mathrm{~nm}$; B \& D, $2 \mu \mathrm{m}$.

GenBank and the study strains were clustered in two sister, sub-clades 1 and 2. Sub-clade 1 (S1) ( $p$-distance $0-1.1 \%$ ) included strains from Korea (MN158649 and MN158648), Brazil (KY288995, KY288993, KY288989, and KY288990), Russia (KU175688), USA (KT899572), Portugal (HM217043), and Sub-Saharan Africa (GQ859650). Subclade 2 (S2) ( $p$-distance 0-0.6\%) included all the Antarctic strains (HQ873482, KU219707, DQ493872, HF678504, and JN979963), one strain from New Zealand (JF925320) and the studied strains (MN656000 and MN656001). The genetic divergences between these two sub-clades range from $0.6-1.4 \%$ (Supplementary Table S1). Our phylogenetic analysis also places P. arthurensis (HQ012544) in the Wilmottia clade ( $p$-distance 1.7-3.4\%).

\section{Wilmottia arthurensis (Novis and Visnovsky) Radzi and Merican comb. nov.}

Basionym. Phormidium arthurense Novis and Visnovsky, Phytotaxa 22: 19, fig. 7G-M ('arthurensis').

Type locality. New Zealand, Westland, Mt. Philistine, Sep 30, 2007, CHR610795. 


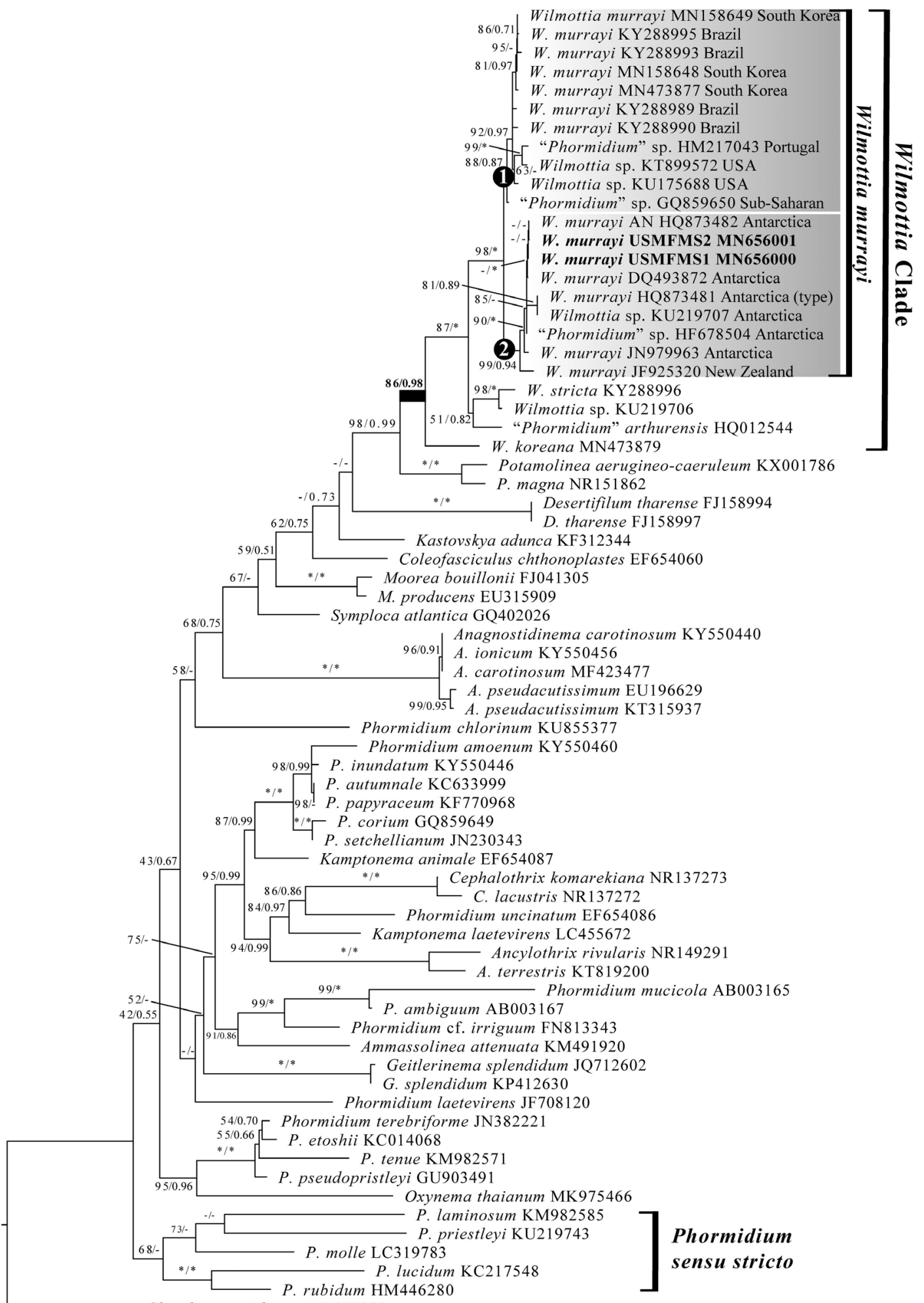

Gloeobacter violaceus NR074282

Fig. 4. Phylogenetic analysis. 16S rDNA gene-based maximum likelihood (ML) phylogenetic tree showing the phylogenetic positions of Wilmottia murrayi USMFMS1 (MN656000) and W. murrayi USMFMS2 (MN656001). ML bootstrap values (left) followed by Bayesian inference bootstrap values (right) on branches. Dashes indicate support values less than $50 \%$. The sequences generated in this study are in boldface. The tree is rooted with Gloeobacter violaceous (NR074282). 


\section{DISCUSSION}

Cyanobacterial classification based solely on morphological characteristics can be challenging, therefore identification using polyphasic approaches is strongly recommended (Komárek 2016). Our 16S rDNA phylogenetic analysis confirms that $W$. murrayi USMFMS1 and $W$. murrayi USMFMS2 are referable to $W$. murrayi despite the differences observed in their morphological characteristics. Our major clade of W. murrayi showed a wellsupported separation of strains from Antarctica and New Zealand from those from other regions.

We suggest that the identity of the three Phormidium sequences (HM217043, GQ859650, and HF678504) that were retrieved from GenBank and clustered with Wilmottia should be-renamed as Wilmottia (Fig. 4). The name Phormidium was applied for strains HM217043 and GQ859650 before the genus Wilmottia was erected by Strunecký et al. (2011). For strain HF678504, the name Phormidium has quite likely been associated with the strain due to lack of critical evaluation of its morphology. If isolates in culture are still available, then the morphology of these could be checked for conformity to W. murrayi. Incorrect taxonomic designation of sequence data from isolated cyanobacteria strains can be highly problematic in modern cyanobacterial taxonomy (Komárek 2016). The morphology and molecular phylogenetic data for $P$. arthurensis as described by Novis and Visnovsky (2011) also suggests that this species would be best placed within Wilmottia (Strunecký et al. 2011) (Fig. 4). We suggest that the genus Wilmottia includes four species: $W$. murrayi (type species), W. stricta, W. koreana, and a new combination $W$. arthurensis.

Morphological differences were evident between our two morphotypes when compared under the same culture conditions and also with previous descriptions of W. murrayi. Both morphotypes were consistent with W. murrayi (West and G. S. West) Strunecký, Elster and Komárek (2011) regarding the apical cell shape and attenuation, granulation, trichome pigmentation, and sheath development, but both had narrower trichomes than the previously recorded minimum of the range for W. murrayi (Strunecký et al. 2011, Machado-de-Lima et al. 2017). Cell shape differed between both morphotypes with cells of $W$. murrayi USMFMS1 being distinctly shorter than wide and those of $W$. murrayi USMFMS2, ranging from isodiametric to shorter and longer than wide (Fig. 2). In previous descriptions, cell shape of $W$. murrayi has been described as isodiametric to longer than wide. Both morphotypes formed necridic cells, but this had not been recorded previously. Fascicle formation was absent in both morphotypes, although Strunecký et al. (2011) considered fasciculation of trichomes to be a characteristic of the genus. Lack of fasciculation has also been reported for Brazilian strains of W. murrayi, but fascicles did occur in W. stricta (Machado-de-Lima et al. 2017).

Previous records of $W$. murrayi showed varying degrees of constriction from unconstricted to slightly constricted (Strunecký et al. 2011). Our W. murrayi USMFMS1 was distinctly constricted at cross walls whilst $W$. murrayi USMFMS2 lacked constrictions (Fig. 2). The Brazilian strains of W. murrayi also had constrictions (Machadode-Lima et al. 2017). Although the absence of distinct constrictions was proposed by Strunecký et al. (2011) to be diagnostic for the genus the evidence now suggests otherwise. Additionally, this characteristic cannot be diagnostic for the Family Coleofasciculaceae (Komárek et al. 2014). Phenotypic identification of Wilmottia is said to be possible based on trichome width, absence of attenuation, constriction and a calyptra (Strunecký et al. 2011). However, constriction of trichomes at cross walls, apical cell shape and cell dimensions differed between our two strains when cultured under identical conditions. Therefore, we conclude that separation of the genus Wilmottia based solely on morphological traits is not recommended and can result in unreliable and erroneous identification. Furthermore, the levels of differentiation apparent between the different strains examined in this study, and currently assigned to $W$. murrayi, suggest that a reassessment of the taxonomic status of these sub-clades would be appropriate, and that the current taxon may represent a species group rather than a single species.

In the ultrastructure analysis, the arrangement of parietal thylakoids in concentric layers and with some thylakoid stacks irregularly penetrating the interior of the cell for both morphotypes conformed to that found in other strains of Wilmottia as well as in other species in the Coleofasciculaceae (Strunecký et al. 2011, Komárek et al. 2014). The solitary granules are polyphosphates and carboxysomes (Fig. 3C).

Our study of two cyanobacterial morphotypes isolated from terrestrial habitats in Signy Island resulted in the identification of the species $W$. murrayi. This species was originally described from Antarctica (Taton et al. 2006, Strunecký et al. 2010) and our results extend its distribution within the region. Recent records of its occurrence in New Zealand (Strunecký et al. 2011) and Brazil (Machado-de-Lima et al. 2017) show a more cosmopolitan distribution. 


\section{ACKNOWLEDGEMENTS}

We thank Dr. Japareng Lalung for collection of soil samples from Signy Island and the staff at the British Antarctic Survey (BAS) Signy Island research station for logistical and other practical support. We thank Laura Gerrish (BAS Mapping and Geographic Information Centre) for preparation of the map in Fig. 1. This study received funding support from YPASM Berth Support, YPASM Fellowship 304/PBIOLOGI/650963, RUI grant 1001/PBIOLOGI/811305 and Flagship grant 304/PBIOLOGI/650723/ P131. Peter Convey is supported by NERC core funding to the BAS 'Biodiversity, Evolution and Adaptation' Team. This study contributes to the international SCAR 'State of the Antarctic Ecosystem' (AntEco) research programme.

\section{CONFLICTS OF INTEREST}

The authors declare that they have no potential conflicts of interest.

\section{SUPPLEMENTARY MATERIALS}

Supplementary Table S1. Un-corrected genetic distance ( $p$-distance) within clades of Wilmottia (https:// www.e-algae.org).

\section{REFERENCES}

Bolch, C. J. S. \& Blackburn, S. I. 1996. Isolation and purification of Australian isolates of the toxic cyanobacterium Microcystis aeruginosa Kütz. J. Appl. Phycol. 8:5-13.

Boyer, S. L., Flechtner, V. R. \& Johansen, J. R. 2001. Is the 16S23S rRNA internal transcribed spacer region a good tool for use in molecular systematics and population genetics? A case study in cyanobacteria. Mol. Biol. Evol. 18:1057-1069.

Boyer, S. L., Johansen, J. R., Flechtner, V. R. \& Howard, G. L. 2002. Phylogeny and genetic variance in terrestrial $\mathrm{Mi}$ crocoleus (Cyanophyceae) species based on sequence analysis of the 16S rDNA gene and associated 16S-23S ITS region. J. Phycol. 38:1222-1235.

Broady, P. A. 1979. The terrestrial algae of Signy Island, South Orkney Islands, Vol. 98. British Antarctic Survey Scientific Reports. British Antarctic Survey, Cambridge, 117 pp.

Casamatta, D. A., Johansen, J. R., Vis, M. L. \& Broadwater, S. T. 2005. Molecular and morphological characterization of ten polar and near-polar strains within the Oscillatoriales (Cyanobacteria). J. Phycol. 41:421-438.

Comte, K., Šabacká, M., Carré-Mlouka, A., Elster, J. \& Komárek, J. 2007. Relationships between the Arctic and the Antarctic cyanobacteria; three Phormidium-like strains evaluated by a polyphasic approach. FEMS Microbiol. Ecol. 59:366-376.

Heath, M. W., Wood, S. A. \& Ryan, K. G. 2010. Polyphasic assessment of fresh-water benthic mat-forming cyanobacteria isolated from New Zealand. FEMS Microbiol. Ecol. 73:95-109.

Kanehisa, M., Goto, S., Sato, Y., Furumichi, M. \& Tanabe, M. 2011. KEGG for integration and interpretation of largescale molecular data sets. Nucl. Acids Res. 40:109-114.

Kearse, M., Moir, R., Wilson, A., Stones-Havas, S., Cheung, M., Sturrock, S., Buxton, S., Cooper, A., Markowitz, S., Duran, C., Thierer, T., Ashton, B., Meintjes, P. \& Drummond, A. 2012. Geneious Basic: an integrated and extendable desktop software platform for the organization and analysis of sequence data. Bioinformatics 28:16471649.

Komárek, J. 2016. A polyphasic approach for the taxonomy of cyanobacteria: principles and applications. Eur. J. Phycol. 51:346-353.

Komárek, J. \& Anagnostidis, K. 2005. Cyanoprokaryota. Teil 2: Oscillatoriales. In Budel, B., Gartner, G., Krienitz, L. \& Schagerl, M. (Eds.) Süsswasserflora von Mitteleuropa; Band 19/2. Spektrum Akademischer Verlag, Heidelberg, pp. 1-759.

Komárek, J., Kaštovský, J., Mareš, J. \& Johansen, J. R. 2014. Taxonomic classification of cyanoprokaryotes (cyanobacterial genera) 2014, using a polyphasic approach. Preslia 86:295-335.

Komárek, J., Kaštovský, J., Ventura, S., Turicchia, S. \& Šmarda, J. 2009. The cyanobacterial genus Phormidesmis. Algol. Stud. 129:41-59.

Lee, N. -J., Seo, Y., Ki, J. -S. \& Lee, O. -M. 2020. Morphology and molecular description of Wilmottia koreana sp. nov. (Oscillatoriales, Cyanobacteria) isolated from the Republic of Korea. Phytotaxa 447:237-251.

Lokmer, A. 2007. Polyphasic approach to the taxonomy of the selected oscillatorian strains (Cyanobacteria). M.S. thesis, Faculty of Sciences, University of South Bohemia, České Budějovice, Czech Republic, 40 pp.

Machado-de-Lima, N. M., Martins, M. D. \& Branco, L. H. Z. 2017. Description of a tropical new species of Wilmottia (Oscillatoriales, Cyanobacteria) and considerations about the monophyly of $W$. murrayi. Phytotaxa 307:4354.

McDowell, E. M. \& Trump, B. F. 1976. Histologic fixatives suit- 
able for diagnostic light and electron microscopy. Arch. Pathol. Lab. Med. 100:405-414.

Novis, P. M. \& Visnovsky, G. 2011. Novel alpine algae from New Zealand: cyanobacteria. Phytotaxa 22:1-24.

Rambaut, A. 2009. FigTree version 1.3.1. Computer program distributed by the author. Available from: http://tree. bio.ed.ac.uk/software/figtree. Accessed Oct 30, 2019.

Reynolds, E. S. 1963. The use of lead citrate at high $\mathrm{pH}$ as an electron-opaque stain in electron microscopy. J. Cell Biol. 17:208-212.

Rippka, R., Deruelles, J., Waterbury, J. B., Herdman, M. \& Stanier, R. Y. 1979. Generic assignments, strain histories and properties of pure cultures of cyanobacteria. J. Gen. Microbiol. 111:1-61.

Ronquist, F. \& Huelsenbeck, J. P. 2003. MrBayes 3: Bayesian phylogenetic inference under mixed models. Bioinformatics 19:1572-1574.

Šabacká, M. \& Elster, J. 2004. Response of algal and cyanobacterial communities from Arctic and Antarctic wetland habitats to freezing and desiccation stress. In XXX Międzynarodowe Sympozjum Polarne, Gdynia, pp. 181-182.

Spurr, A. R. 1969. A low-viscosity epoxy resin-embedding medium for electron microscopy. J. Ultrastruct. Res. 26:31-43.

Stecher, G., Tamura, K. \& Kumar, S. 2020. Molecular Evolu- tionary Genetics Analysis (MEGA) for macOS. Mol. Biol. Evol. 37:1237-1239.

Strunecký, O., Elster, J. \& Komárek, J. 2010. Phylogenetic relationships between geographically separate Phormidium cyanobacteria: is there a link between north and south polar regions? Polar Biol. 33:1419-1428.

Strunecký, O., Elster, J. \& Komárek, J. 2011. Taxonomic revision of the freshwater cyanobacterium "Phormidium" murrayi $=$ Wilmottia murrayi. Fottea 11:57-71.

Taton, A., Grubisic, S., Ertz, D., Hodgson, D. A., Piccardi, R., Biondi, N., Tredici, M. R., Mainini, M., Losi, D., Marinelli, F. \&Wilmotte, A. 2006. Polyphasic study of Antarctic cyanobacterial strains. J. Phycol. 42:1257-1270.

Trifinopoulos, J., Nguyen, L. -T., von Haeseler, A. \& Minh, B. Q. 2016. W-IQ-TREE: a fast online phylogenetic tool for maximum likelihood analysis. Nucleic Acids Res. 44:W232-W235.

West, W. \& West, G. S. 1911. Freshwater algae. In Murray, J. (Ed.) Biology, Vol. 1. Reports on the Scientific Investigation, British Antarctica Expedition 1907-09. Heinemann, London, pp. 263-298.

Wood, S. A., Hamilton, D. P., Paul, W. J., Safi, K. A. \& Williamson, W. M. 2009. New Zealand Guidelines for cyanobacteria in recreational fresh waters: interim guidelines. Ministry for the Environment and Ministry of Health, Wellington, $82 \mathrm{pp}$. 